ISSN: 2644-1209

\title{
An Ophthalmologist look at Art
}

\author{
Jorge Meyrán García* \\ Hospital career history in the Hospital General de México
}

*Corresponding author: Jorge Meyrán García, Hospital career history in the Hospital General de México, Mexico

\section{Introduction}

In the 1990s Dr. María Dolores Cortés lent me a very interesting book called "An Ophthalmologist look at art" written by Arthur Linksz M.D. The author makes several analyses, observations and conjectures about the portraits of people who accepted the indications of the painter, although there were some important persons who wanted to impose his desires and that created problems for the painter; then it's about self-portraits, some made in front of a mirror and others taken from a photograph; later it deals with the direction of reading and writing, from left to right in the western and right to left in the East, and ends with uncapítulo on the commented astigmatism of the Greco. I think an ophthalmologist who likes art, especially painting should have read it. In short, when referring to portraits, he points out that people receive the light on the left side so as not to cover it if the painter is right-handed, except when an important person did not meet the painter's demands. Often with the face turned to the right and the eyes in front. When talking about the self-portraits he first writes down the facts with a mirror, the left side of the painter appeared in the picture as the right. Your left hand can hold a brush while painting with your right hand, so that it appears in the picture as right-handed. Its manor right would not serve as a model and several painters hide it with clothes, fabrics, etc. There are several right-handed contemporary painters who don't care about lefthanded sideren. There are two self-portraits of Gian Lorenzo Bernini, one young made up close and the other adult, more retired. This is related to presbyopia. In contemporary self-portraits it is important to observe the dresses, in the hombre the buttons are $\mathrm{d}$ the right side and the eyelets on the left. In a photograph you see this correct layout. In Manet's retrato author is the other way around, the right side with the eyelets on the left with the buttons, $\mathrm{M}$ anetpinted what he saw. The sacks have in the upper bag on the left side or sometimes on both sides, never from the only right. In the self-portrait of B'cklin is on the left side, it must have been taken from a photograph (actually an etrato photo-author). The direction of reading and writing we do from left to right, it is a Western art, the opposite, from right to left is an oriental art (Figure 1).

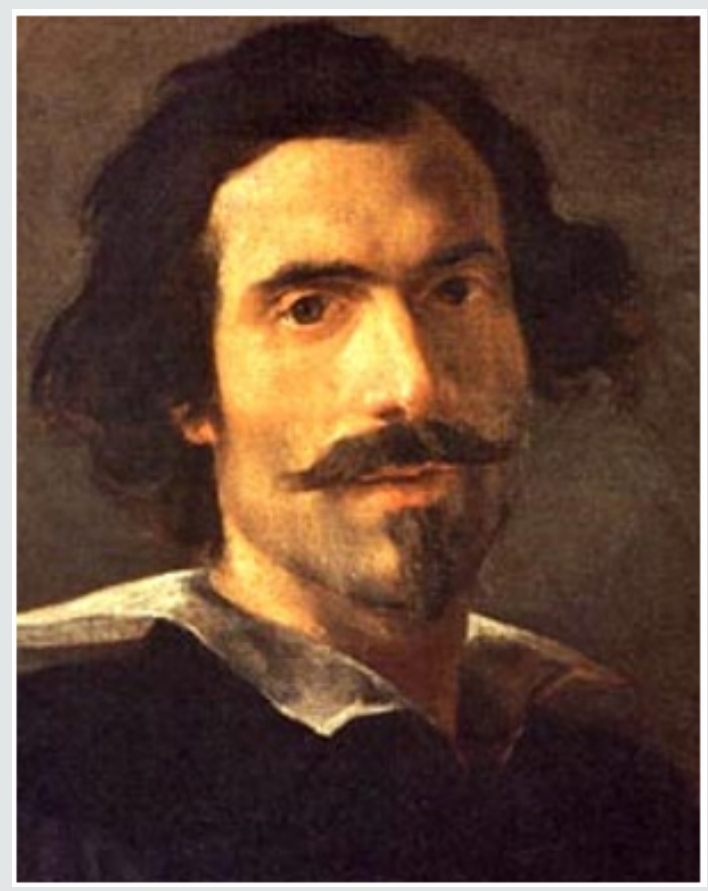

Figure 1: Gian Lorenzo Bernini.

In Occident is already a conditioned reflection read, ver historietas and even pictures from left to drop and in painting also happens that, for example, the procession of blind people of Bregel walks from left to right, instead that of Hohusai, Japanese, does so from right to left. When painting stripes, brushstrokes, shadow lines the right-handed make them from top right to bottom left, on the left-handers from below echa to top left andrda. With regard to the astigmatism of the Greco I did not write anything down, because I already knew that astigmatism gives vision something or very blurred according to the degree, and that the Greco painted hands and faces horizontal and vertical elongated, if the cause was astigmatism would only be in one direction (Figures 2\&3). 

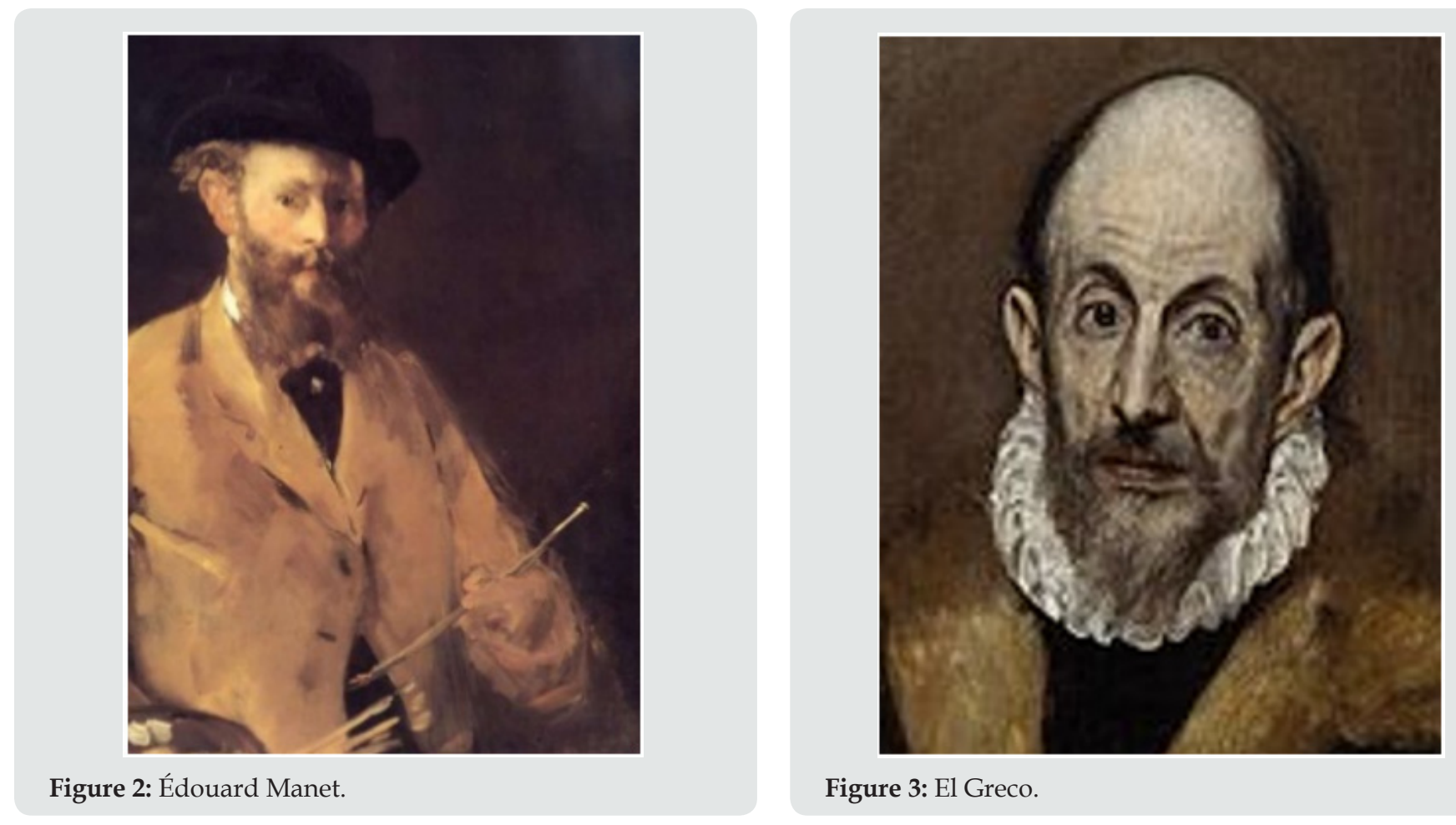

Figure 3: El Greco.

\section{(C) This work is licensed under Creative}

To Submit Your Article Click Here:

Submit Article

DOI: $10.32474 /$ TOOAJ.2020.02.000147

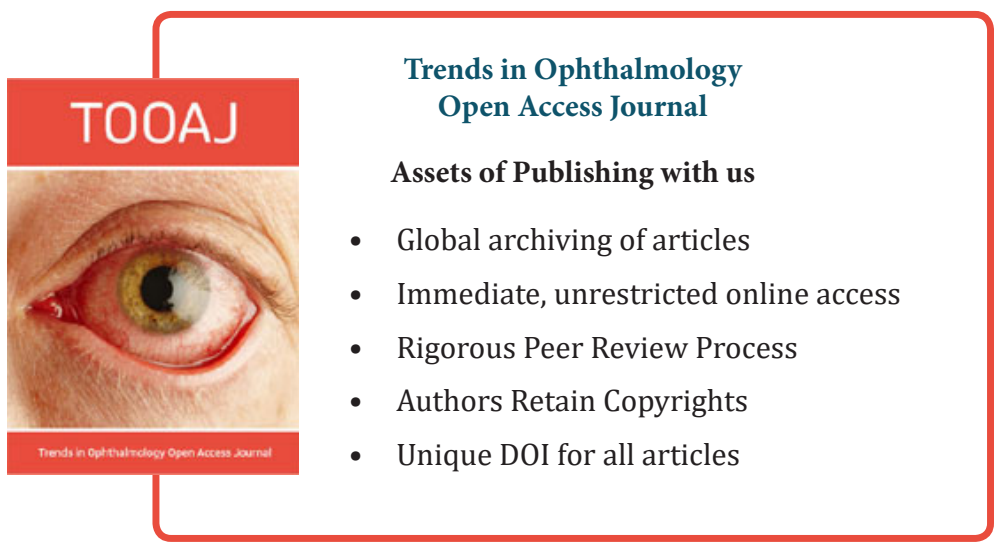

